\title{
EXPERIÊNCIA, PERCEPÇÃO E ESPAÇO URBANO: CONVIVÊNCIA E OCUPAÇÃO RESSIGNIFICANDO O HABITAR A CIDADE
}

\author{
$*$ \\ Chalissa Beatriz Wachholz \\ Pontifícia Universidade Católica do Rio Grande do Sul - PUCRS - Brasil \\ Luciele Nardi Comunello \\ Pontifícia Universidade Católica do Rio Grande do Sul - PUCRS - Brasil
}

\section{Resumo}

O presente artigo busca compreender, através das contribuições da educação ambiental e da psicologia ambiental, bem como de conceitos de experiência e percepção na fenomenologia de Merleau-Ponty, os efeitos da ocupação do espaço urbano através de dois eventos realizados nos principais parques da cidade de Porto Alegre-RS: o "Pique-nique Noturno", realizado nos parques Farroupilha e Moinhos de Vento e o Festival de Comida de Rua, realizado em bairros centrais da cidade. Estes dois eventos assemelham-se por aproximar a alta gastronomia dos espaços públicos, possuem caráter filantrópico, pois promovem doações dos participantes para entidades assistenciais e se apresentam como espaços potenciais para uma experiência acerca do espaço urbano e da convivência de humanos entre si e com o ambiente urbano. Entendemos que a possibilidade de uma experiência nesse contexto pode contribuir para modificar a percepção das pessoas acerca do habitar a cidade e da relação que estabelecem entre si e com o ambiente em que estão inseridas.

Palavras-chave: Psicologia Ambiental; Educação Ambiental; Experiência.

\section{Introdução}

Discussões acerca do meio ambiente têm ganhado, progressivamente, maior visibilidade no cenário das políticas internacionais, dos programas nacionais, do mercado e, inclusive, dos movimentos sociais, principalmente a partir dos anos 70 do século XX. Esse fenômeno pode ser atribuído às constantes mudanças provocadas pela ação humana na natureza e pelas respostas que ela vem dando a essas ações. Segundo Guimarães (1995), a sociedade contemporânea, por herança da Modernidade, acabou por produzir um afastamento entre o ser humano e a natureza. Esta separação está no cerne do projeto moderno de utilização da razão instrumental para domínio da natureza e consequente desenvolvimento da civilização humana. O ser humano não se percebe mais como parte da natureza, agindo de forma totalmente desarmônica no ambiente e sendo protagonista em um cenário de grandes desequilíbrios ambientais. 
No âmbito científico, os pesquisadores, em suas diversas áreas de atuação, têm contribuído de várias maneiras na tentativa de estudar e mitigar as alterações ambientais que as atividades humanas vêm causando no mundo moderno e contemporâneo. Algumas perspectivas atribuem a crise ambiental vivida na atualidade a uma crise epistemológica, vinculada à tradição científica que coloca o ser humano e a natureza em distintos domínios do saber. A natureza, ao lado das ciências duras, objetivas e o ser humano, ao lado das ciências humanas e sociais. Essas abordagens compreendem que um dos desafios das ciências ambientais na atualidade seria a de superar as dicotomias geradas principalmente após a revolução científica: natureza-cultura, objeto-sujeito etc.

Carvalho e Steil (2014) situam um segmento do debate contemporâneo que tem como ponto de convergência o empreendimento de esforços para a superação das dicotomias criadas pela modernidade, tais como: natureza-cutura, sujeito-sociedade, corpo-mente, artifícionatureza, sujeito-objeto na busca de modos ecológicos de compreender interações com o mundo. Os autores nomeiam essa região de debate, composta por diversos pensadores, de "Epistemologias Ecológicas". Em consonância com o movimento conhecido como virada ontológica, as epistemologias ecológicas enfatizam uma simetria nas relações entre humanos e não humanos em seu ambiente. Neste caminho, criticam as perspectivas representacionistas, abandonando um mundo de abstrações apartado da matéria para compreender o processo de construção de conhecimento como um engajamento do corpo no mundo: "conhecer é fundamentalmente uma habilidade que adquirimos na relação com outros organismos e seres que habitam o mesmo mundo [...]" (CARVALHO, STEIL, 2014).

Assim, partindo com esta perspectiva, a percepção do espaço no qual vivemos está relacionada a um processo de imersão dos corpos, como todos integrados, em engajamento com o ambiente, a partir do qual ser e mundo se constituem mutuamente, em um movimento de reciprocidade. A percepção como parte do processo de aprender, consiste em um "engajamento ativo e exploratório da pessoa inteira, corpo e mente indissolúveis, num ambiente ricamente estruturado" capaz de incluir "como as pessoas, na prática, veem, ouvem e tateiam em suas próprias vidas"(INGOLD, 2008, p. 1).

A questão da interação entre o humano e o ambiente se complexifica, portanto, consideravelmente, revelando a necessidade de uma visão que ultrapasse as fronteiras disciplinares e conceituais. Essa relação é mediada pela percepção e, para estudar essa interação humano-ambiente buscando a superação de uma visão dicotômica, é fundamental que a percepção seja analisada para além do ponto de vista meramente cognitivo. A percepção que 
temos das condições ambientais em que vivemos é construída a partir das nossas experiências dessas condições, dos espaços que habitamos e que, de certo modo, criamos de modo conjunto. Essa criação conjunta se dá justamente porque, para os seres humanos, o espaço físico e biológico é integrado ao "espaço" sociocultural, no qual a interação com os elementos do ambiente provoca modificações que, por sua vez, se transformam de modo contínuo com o passar do tempo. Ao transformar o ambiente, os seres humanos também transformam o seu olhar a respeito do meio em que vivem.

Levando em conta as questões trazidas até aqui, o presente artigo busca compreender, através dos conceitos de experiência e percepção na fenomenologia de Merleau-Ponty, os efeitos da tomada do espaço urbano - entendido como contexto de educação não formal - nos modos de habitar a cidade. Como exemplos para esta reflexão, escolhemos dois eventos: o Pique-nique Noturno (realizado nos principais parques da cidade - Parque Farroupilha e Moinhos de Vento) e o Festival de Comida de Rua, ambos realizados no município de Porto Alegre-RS. Esses eventos se apresentam como espaços potenciais para uma experiência acerca do espaço urbano e da convivência de humanos entre si e com o ambiente urbano. Entendemos que a possibilidade de uma experiência nesse contexto pode contribuir para modificar a percepção das pessoas acerca do habitar a cidade e da relação que estabelecem entre si e com o ambiente em que estão inseridas. Para a construção desse argumento, iniciaremos com uma breve recapitulação dos conceitos de experiência e percepção que, na obra de Merleau-Ponty aparecem como correlatos. A segunda seção aborda brevemente a relação do humano com seu entorno - com foco nas questões socioambientais vividas no ambiente urbano - e a possibilidade de transformação de ambos de forma conjunta e recursiva ao longo do tempo. Por fim, descreveremos as iniciativas ocorridas na cidade de Porto Alegre, situando-as como estratégias que podem contribuir para uma experiência do espaço urbano, com importantes repercussões socioambientais.

\section{Experiência e Percepção na Fenomenologia: contribuições para o campo ambiental}

Merleau-Ponty, filósofo tributário da fenomenologia e discípulo de Husserl, a define como uma "filosofia que repõe as essências na existência" $(1999$, p.2). Sua visão imanente e crítica à metafísica retoma o radical papel dos sentidos e devolve o Ser ao mundo, na medida em que concebe que só podemos compreendê-lo em sua facticidade. Por este motivo, a experiência possui um lugar importante em sua obra. Para este pensador, a experiência do 
mundo em si é fundante de qualquer conhecimento que possamos ter a respeito dele: "minha experiência não provém de meus antecedentes, de meu ambiente físico e social, ela caminha em direção a eles e os sustenta, pois sou eu quem faz ser para mim” (p. 3).

Ao mesmo tempo, a fenomenologia tece uma crítica à tradição idealista, colocando o mundo como pré-existente e a experiência como condição para que os símbolos possam nos dizer alguma coisa, nos fazer algum sentido. O conceito de experiência, então, não está muito afastado do conceito de percepção e ambos retomam o papel das sensações, em que "a sensação não é nem um estado ou uma qualidade, nem a consciência de um estado ou de uma qualidade, como definiu o empirismo e o intelectualismo. As sensações são compreendidas em movimento" enquanto corpos se engajam na paisagem - a percepção passa ser, então, "uma atitude corpórea”, o que remete à noção de experiência. Neste sentido o autor enfatiza o papel da experiência do corpo na construção de sentidos sobre o mundo (NOBREGA, 2008, p. 142).

Para este pensador, a análise perceptiva se desdobra em sensibilidade estética, considerando o corpo, o movimento e o sensível como dimensões da corporeidade. Assim, a percepção deriva de uma sinergia entre o sensório e o motor - os órgãos sensoriais e os músculos (como elementos articulados entre si).

Merleau-Ponty busca romper com a dicotomia essência e existência, mostrando como os sentidos do mundo encontram-se na existência, definindo as coisas percebidas. Para este autor, percepção é sempre consciência perceptiva de alguma coisa e nela não se pode separar o sujeito e o objeto. Para ele,

construímos a percepção com o percebido. E, como o próprio percebido só é evidentemente acessível através da percepção, não compreendemos finalmente nem um nem outro. Estamos presos ao mundo e não chegamos a nos destacar dele para passar à consciência do mundo. Se nós o fizéssemos, veríamos que a qualidade nunca é experimentada imediatamente e que toda consciência é consciência de algo. (MERLEAU- PONTY, 1999, p. 26).

Na percepção, as decomposições analíticas são precedidas pela imagem do todo, este é o legado da psicologia da Gestalt no pensamento de Merleau-Ponty. Esta psicologia voltou-se ao estudo da percepção humana como uma totalidade (Gestalt) e assumiu a noção de que a totalidade perceptiva é sempre mais do que a soma das partes percebidas e as precede. Na obra Fenomenologia da percepção o autor explica que considera seu próprio corpo como seu ponto de vista sobre o mundo (1999, p. 85). Dessa forma, ele tem consciência de seu corpo através do mundo e tem consciência do mundo devido a seu corpo (1999, p. 87). No entanto, a forma como se percebe o mundo e seus fenômenos também está vinculada à cultura e à sociedade, o que não 
permite que à percepção seja "neutra", imparcial ou pura, pois ela sofre influências e contágios culturais e sociais.

A percepção, assim,

não é uma ciência do mundo, não é nem mesmo um ato, uma tomada de posição
deliberada; ela é o fundo sobre o qual todos os atos se destacam e ela é pressuposta
por eles. O mundo não é um objeto do qual possuo comigo a lei de constituição; ele
é o meio natural e o campo de todos os meus pensamentos e de todas as minhas
percepções explícitas. (MERLEAU-PONTY, 1999, p.6)

A experiência da percepção nos coloca numa relação íntima e constante com o mundo vivido. Isso nos faz notar que a percepção não é um processo fisiológico isolado, mas uma base onde os atos como ver, caminhar, rir, chorar, abraçar, pensar, dentre outros, se sustentam e interligam-se como uma teia de fios fortemente tramada. Esta analogia demonstra que a percepção não deve ser tida como uma sensação isolada, mas no entrelaço de um todo que possui um sentido.

\begin{abstract}
O homem existe como ser-no-mundo pelo seu corpo. Não é alguém que se encontra objetivamente como simples coisa no meio do mundo, nem uma consciência encerrada na sua interioridade. Realiza-se como para si - como consciência e liberdade - no ato de sair de si e estar junto das coisas em relação com o mundo e os outros homens. [...] Ele é, em sentido forte, "um sujetvouéou monde", um sujeito que tem no mundo sua destinação. (NOGUEIRA, 2007, p.20)
\end{abstract}

Trazendo esta temática para dentro da psicologia ambiental, a nossa consciência, em todas as suas atividades, desde a percepção até a atividade científica, incluindo imaginação e sentimento, compõem um campo de manifestação que se revela como existência ou modo de ser próprio que nos define como seres de sentido, capazes de se compreender e compreender o mundo no qual esse sentido se inscreve.

Para Evans (1983), a principal questão dentro da psicologia ambiental, é como o ser humano começa a compreender os diferentes ambientes do seu mundo real. Cada indivíduo percebe, reage e responde diferentemente diante das questões sobre o ambiente e esta "variação de respostas" é resultado da percepção de cada um (FAGGIONATO, 2002). Com isso, a compreensão do ambiente como uma realidade complexa baseia-se na interconexão do que está fora e dentro dos espaços educativos - nos espaços não formais, na realidade local e global, no social e no ambiental (GUIMARÃES, 2003).

O conhecimento sensível possui um papel nessa compreensão. Também chamado de conhecimento empírico ou experiência sensível é composto de sensação e percepção. A sensação é o que nos dá as qualidades exteriores e interiores, ou seja, as qualidades dos objetos e os efeitos internos dessas qualidades sobre nós. Na sensação vemos, tocamos, sentimos, 
ouvimos qualidades puras e diretas: cores, odores, sabores, texturas. Sentimos o quente e o frio, o doce e o amargo, o liso e o rugoso, o vermelho, o verde, etc. Sentir é algo dúbio, pois o sensível é, ao mesmo tempo, a qualidade que está no objeto e o sentimento interno que nosso corpo possui das qualidades sentidas. Por isso, costuma-se dizer que a sensação é uma reação corporal imediata a um estímulo ou excitação externa, sem que seja possível distinguir, no ato da sensação, o estímulo exterior e o sentimento interior. (CHAUÍ, 1998). Se prestarmos atenção numa sensação, não vamos somente dizer que sentimos o calor, engolimos o doce ou vemos a cor, mas acrescentamos à frase o que, de fato, dá sentido a estes adjetivos: o ferro está quente, a árvore é verde e o alimento está doce. Isto é, sentimos as qualidades como integrantes de seres mais amplos e complexos do que a sensação isolada de cada qualidade. Por isso, se diz que, na realidade, só temos sensações sob forma de percepções, ou seja, de uma síntese de sensações.

Para a teoria fenomenológica do conhecimento, a percepção é vista originária e parte principal do conhecimento humano, todavia, com uma estrutura diferente do pensamento abstrato, que atua com ideias. Neste sentido, a percepção sempre se realiza por perfis ou perspectivas, ou seja, não se percebe de uma só vez um objeto, uma vez que é possível perceber algumas de suas faces por vez, diferentemente de um pensamento, onde nosso intelecto compreende uma ideia de uma só vez e por inteiro, sem precisar examinar cada uma de suas “faces”. (CHAUÍ, 1998, p. 124).

Merleau-Ponty acrescenta a esta discussão, dando um exemplo de como alguém percebe o ladrilhado no fundo de uma piscina. Para esta imagem, ele explica que percebê-la é perceber os reflexos das árvores na água, as nuances de cor no líquido, a movimentação dos ladrilhos.

Quando eu vejo, através da espessura da água, o ladrilhado no fundo da piscina, não
o vejo apesar da água, dos reflexos; vejo o justamente através deles, por eles. Se não
houvera essas distorções, essas zebruras de sol; se eu visse sem esta carne a geometria
do ladrilhado, então é que cessaria de o ver como ele é, onde ele está, a saber: mais
longe do que qualquer lugar idêntico. A própria água, o poder aquoso, o elemento
xaroposo e cintilante, não posso dizer que esteja no espaço: ela não está noutro lugar,
mas também não está na piscina. Habita-a, nela se materializa, nela não está contida,
e, se ergo os olhos para a tela dos ciprestes onde brinca a rede dos reflexos, não posso
contestar que a água a visita também, ou pelo menos a ela envia a sua essência ativa
e viva. (MERLEAU- PONTY, 1975 p. 294)

Não estamos recebendo estímulos que formarão impressões no cérebro: estamos percebendo uma forma organizada. Do mesmo modo que, frente a esta imagem, não se vê ilusões visuais, como ladrilhos apesar da água que os deformaria. Vê-se e percebe-se ladrilhos ao fundo de uma piscina, ou seja, formas móveis no chão e nas paredes da mesma. Isso é perceber. 
Para Chauí (1998, p. 125), “a percepção se realiza num campo perceptivo e o percebido não está "deformado" por nada, pois ver não é fazer geometria nem física". Não há ilusões na percepção o que a diferencia do pensamento. A percepção não é ocasionada por objetos sobre nós, nem mesmo pelo efeito do nosso corpo sobre os objetos. Ela é uma relação entre objetos e nós e nós e objetos, uma vez que objetos são corpos e nós também somos corporais.

Nogueira acrescenta que

\begin{abstract}
o resultado da percepção, a coisa percebida nos é dada como coisa presente no mundo que captamos através de perspectivas que fluem interruptamente em nosso campo perceptivo. Ora, esse encontro com o mundo pelo qual o revelamos é algo que se realiza intersubjetivamente, na relação com os outros por meio da linguagem. A nossa consciência, em razão da intencionalidade, ao revelar o mundo ao mesmo tempo revela-se a si mesma, pois o seu ato de revelar é correlativo ao significado que o mundo descobre. A consciência humana é sempre consciência-no-mundo ligada indissociavelmente a ele pelo corpo. (NOGUEIRA, 2007, p.21).
\end{abstract}

A percepção, portanto, está intimamente relacionada à atitude corpórea e essa perspectiva ancora-se num ponto essencial - o movimento. Para Merleau-Ponty, a percepção do corpo é confusa na imobilidade, pois lhe falta a intencionalidade do movimento. Para ele, "o meio se destaca do mundo segundo o ser do organismo, estando claro que um organismo não pode existir, salvo, se encontra no mundo um meio adequado" (1975b, p.39). Ainda para o autor, "os movimentos, à medida que se executam, provocam modificações no estado do sistema aferente que, por sua vez, criam novos movimentos”. (1975b, p.73). Considerando a experiência do movimento, corpo e consciência apresentam-se como unidade. O corpo, assim, revela o sujeito que percebe e o objeto percebido. É por meio dele, através dos órgãos sensitivos, que vivemos a experiência de uma relação com o mundo. Num movimento que ele denomina "saindo" (outgoing) o sujeito vai ao encontro do mundo e, neste encontro, o corpo toma os traços dos lugares que conheceu.

Os lugares por sua vez, também são alterados pelo corpo simultaneamente e o mundo se internaliza, enraizando-se no "Eu", num movimento oposto que ele denomina "entrando" (incoming). O lugar marca sua presença no corpo, reside neste através de nosso caráter e esse duplo movimento é infindável. Se os corpos sentem e dão sentido ao mundo à medida que se deslocam, o movimento corporal nos instiga a compreender como é que os indivíduos enquanto indivíduos sociais móveis constroem e reconstroem narrativas acerca do meio em que estão inseridos.

Tim Ingold em seu artigo "Da Transmissão de Representações à Educação da Atenção" (2010, p. 14) afirma que o movimento corporal de um praticante é, ao mesmo tempo, "um movimento de atenção; porque ele olha, ouve e sente, mesmo quando trabalha". E este 
movimento responde contínua e fluentemente a mudanças do ambiente percebido. Ingold, assim como Merleau-Ponty, aproxima sua teoria da fenomenologia e afirma que conhecer não é o resultado da aquisição das representações, mas da disposição dos sujeitos no mundo de forma a forjar certas habilidades a partir desta relação. Para este autor, a caminhada é parte da configuração humana.

\section{O Campo ambiental: contribuições da Psicologia e da Educação}

A Psicologia Ambiental é a área da psicologia que, de acordo com Moser (1998, p. 122), "estuda a pessoa em seu contexto, tendo como tema central as inter-relações - e não somente as relações - entre a pessoa e o ambiente físico e social". Esta área de pesquisa tem como objeto de estudo a relação e as inter-relações entre pessoa e ambiente, bem como os processos afetivos e cognitivos envolvidos no ambiente social, histórico, cultural e físico. As contribuições da fenomenologia, neste campo, podem auxiliar a compreensão dessa relação menos a partir de uma concepção dos esquemas mentais, cognitivos e mais pela via do ser como um todo integrado, engajado nas suas atividades no meio em que está inserido, com a comunidade em que vive.

Moser (1998) considera também as dimensões sociais e culturais como elementos que intervêm na definição dos ambientes que influenciam na percepção e no julgamento do indivíduo diante do ambiente. Para ele, a Psicologia Ambiental estuda esta inter-relação entre o indivíduo e o ambiente de forma dinâmica, levando em conta tanto os ambientes naturais como aqueles modificados pelo homem, numa interação que, ao longo dos anos vai interferindo e transformando as condutas humanas e o meio ambiente. Assim, é interessante mencionar esta ampliação do conceito de socioambiental, que inclui as dimensões psíquicas, sociais e ambientais como um contínuo. Deste modo, quando nos referimos a essas questões não estamos somente nos remetendo às problemáticas vividas no espaço urbano como a poluição do ar, das águas, o tratamento adequado dos resíduos, a conservação de espécies (fauna e flora) locais, mas também aos problemas de segurança, de ocupação do espaço público, das estratégias políticas de reivindicação e da convivência na cidade.

Muitos estudos na área da Psicologia Ambiental têm mostrado que valores, crenças, atitudes, preocupação com o ambiente, condições ambientais e estilo de vida influenciam no comportamento ecológico. No entanto, o ambiente incorpora os valores sociais e culturais daqueles que vivem nele e a cultura tem uma interferência global. Aqui buscamos dar ênfase a 
esse aspecto na observação do local, visto que sujeito e mundo se constituem mutuamente em sua relação, que é sempre situada em um tempo-espaço.

Yázigi (2001) afirma que cada lugar tem uma "personalidade própria" que se ancora no conjunto de suas especialidades, como sua história, seus mitos, sua arquitetura, seus componentes humanos e não humanos, sua forma linguística, além de seus fatores abióticos peculiares (clima, temperatura). Além disso, mesmo havendo lugares com detalhes semelhantes, ainda há o diferencial relacionado ao uso que a comunidade faz de todo conjunto, o que pode produzir diferença, promovendo a identidade do lugar e permitindo que pessoas associem significados simbólicos e afetivos a ele, ficando ligadas tanto cultural quanto emocionalmente. É a partir desse enlace com o ambiente que o comportamento ambiental vai se configurando no indivíduo ou grupo estabelecido em determinado local.

Se a psicologia ambiental foca-se na forma como as pessoas percebem e experienciam o espaço em que estão inseridas, destacando não somente a compreensão dos problemas ambientais, mas, sobretudo, a questão da sustentabilidade da vida enquanto responsabilidade dos seres humanos, a Educação Ambiental (EA) também possui contribuições nesse sentido. A EA pode ser compreendida como uma nova dimensão didático-pedagógica que busca atuar como elemento de transformação nestas relações entre homem e ambiente, contribuindo para a construção da cidadania, autonomia e da melhoria da qualidade de vida.

Para Gaudiano (2005, p. 218), “qualquer educação cumpre um papel instrumental para ajudar a alcançar fins sociais amplos e diversos, mas também tem as duas finalidades substantivas próprias”. Contudo, a EA, enquanto educação é desafiada a encontrar a maneira adequada de propiciar as pessoas situações viáveis de formação de uma consciência ecológica e social de caráter universal, introduzindo-as à ação particular e comunitária para a resolução dos problemas do meio ambiente.

Ao longo dos últimos anos, a EA tem sido cogitada e adotada como fomentadora de ações capazes de colaborar na transformação do padrão de degradação socioambiental vigente. Ela vem contribuindo para modificar as relações entre sociedade e a natureza, buscando melhorias na qualidade de vida e propondo uma transformação de valores e atitudes. Para Carvalho (2006, p. 56), a EA é um processo permanente de aprendizagem, que se baseia no respeito por todas as formas de vida.

Ao compreendermos a ocupação do espaço público como um potente contexto de educação não formal, enfatizamos o papel da experiência nesse processo. Tomar as coisas desse modo é buscar uma via alternativa para a compreensão da educação no âmbito da relação do 
humano com seu meio, valorizando os espaços de interação e contemplação no mundo da vida, como formas de escapar à prática educacional reduzida à aplicação de saberes, a uma artetécnica que parece apartar a existência humana da formação - que objetiva "oferecer aos seus destinatários habilidades e competências, que os conforme ao existente"(PAGNI, 2010, p. 23)

\section{O humano e seu entorno: engajamento e transformação dos espaços e relações}

As múltiplas percepções originadas das vivências com a natureza estimulam sentimentos estéticos e valorativos nem sempre definíveis. Heemann e Heemann (2003) cunham o conceito de topofilia como sendo a percepção, atitudes e ligação do homem ao ambiente, "o elo afetivo entre a pessoa e o lugar ou ambiente físico" (TUAN, 1980, p.106).

Estes conceitos nascem no campo da chamada "Geografia Humana", que estuda as relações dos agrupamentos humanos com o meio geográfico, que engloba não somente as influências naturais que podem exercer, mas ainda uma influência que contribui para formar o meio geográfico, o ambiente total, a influência do próprio homem.

Tuan (1980) traz a discussão a respeito da percepção do meio ambiente à luz da subjetividade e da experiência, destacando a participação das "coisas" no mundo para os sentidos que damos a ele.O autor destaca que“o meio ambiente pode não ser a causa direta da topofilia, mas fornece o estímulo sensorial que, ao agir como imagem percebida, dá forma às nossas alegrias e ideais" (1980, p. 129). O foco de nossa atenção, aquilo que valorizamos ou amamos "é um acidente do temperamento individual, do propósito e das forças culturais que atuam em determinada época" (1980, p. 129). Também Merleau-Ponty (1991) nos oferece ferramentas para pensarmos nessa interação entre humanos e seu meio a partir de uma abordagem não dicotômica. Ela inicia com o questionamento "Para que se perguntar se a história é feita pelos homens ou pelas coisas, já que om toda a evidência as iniciativas humanas não anulam o peso das coisas e a "força das coisas" opera sempre através dos homens?" E responde:

É justamente esse malogro da análise, quando ela quer restringir tudo a um único plano, que desvela o verdadeiro meio da história. Não há uma análise que seja a derradeira porque há uma carne da história que, tanto nela como em nosso corpo. Contem tudo, engloba tudo - tanto a infra-estrutura quanto a ideia que fazemos dela, e sobretudo as perpétuas trocas entre uma e outra, nas quais o peso das coisas tornase signo também, os pensamentos forças, o balanço acontecimento. (MERLEAUPONTY, 1991, p. 20)

O entendimento da relação entre percepção e meio ambiente tem, dessa forma, um importante papel na compreensão de conflitos que envolvem o planejamento ambiental, tanto 
no que diz respeito à utilização de recursos naturais quanto as estratégias de educação ambiental para mudar o cenário atual no contexto das cidades. Compreendemos que a criação de espaços que contribuam para uma experiência outra do espaço urbano, rompendo com as disposições cotidianas, podem ser profícuos para a modificação do modo como os habitantes da cidade percebem seu entorno, através de seu engajamento corpóreo no ambiente, sendo assim, capaz de modificar a compreensão de seus modos de habitar o mundo e, consequentemente sua ação transformadora junto dele.

A capacidade de transformação mútua do humano em seu ambiente é chamada na biologia de co-evolução. Essa abordagem entende que o ambiente afeta o modo como percebemos, sentimos e agimos frente aos fatores contextuais físicos e que as percepções, sentimentos e ações afetam os componentes sociofísicos do ambiente. "Se a vida é um processo de conhecimento, os seres vivos constroem esse conhecimento, não a partir de uma atitude passiva e sim pela interação. Aprendem vivendo e vivem aprendendo". (MATURANA \& VARELA, 2005, p.12).

Os conceitos, bem como a percepção que o indivíduo tem do ambiente, podem contribuir para compreensão dos problemas socioambientais, influenciando no maior envolvimento e participação dos indivíduos ou grupos nas questões que lhes dizem respeito.

A percepção ambiental está relacionada ao modo como as pessoas experenciam os aspectos ambientais presentes em seu entorno, para que são importantes não apenas os aspectos físicos, mas também os aspectos sociais, culturais e históricos. (KUHNEN e HIGUCHI, 2011, p.250).

O desenvolvimento do pensamento abstrato, da linguagem simbólica e de outras capacidades humanas depende, essencialmente, do fenômeno da "consciência", que, segundo o biólogo alemão Ernst Mayr, é uma característica moldada pela evolução ${ }^{1}$, emergida, portanto, da consciência dos animais, o que não é difícil de aceitar, uma vez que a consciência possa ter prevalecido na evolução porque conhecer os sentimentos causados pelas emoções era absolutamente indispensável para a arte de viver, e porque a arte de viver foi realmente um sucesso na história da natureza. Somos, portanto, seres conscientes de nossas sensações, tanto quanto de nós próprios como indivíduos pensantes e experientes. Nossas respostas ao meio ambiente são, contudo, determinadas não tanto pelo efeito direto e sensações captadas pelo

\footnotetext{
${ }^{1}$ A partir dos estudos com primatas não-humanos, publicados na década de 60, a defesa dogmática de que a inteligência seria um dom exclusivo de seres humanos tornou-se insustentável. Compreender a inteligência de que tanto nos orgulhamos como resultado de milhões de anos de seleção natural obedece à lógica evolutiva, visto que a evolução não cria características especiais para favorecer ou prejudicar qualquer espécie.
} 
nosso sistema biológico, mas, antes, por nossa experiência passada, nossas expectativas, nossos escopos e pela interpretação individual de nossa experiência perceptiva.

\section{Estratégias de outras ocupações dos espaços urbanos: Porto Alegre, um estudo de caso}

Os eventos escolhidos para análise neste artigo foram selecionados por proporcionarem a abertura para a vivência do espaço urbano de outros modos que não os da rotina cotidiana. Os dois guardam a semelhança de terem sido impulsionados, entre outros motivos, pelo desejo de levar a alta gastronomia para as ruas, para o espaço público. Levar a alta gastronomia para o espaço público tem como efeito o acesso a esta experiência para pessoas que de outro modo não poderiam acessá-la² .

Além disso, o comer na rua também constitui uma forma inusitada de ocupar o espaço, podendo proporcionar uma experiência contemplativa que rompe com o ritmo acelerado do cotidiano, possibilitando um caminhar lento e desinteressado capaz de apreciar a paisagem que se desvela quando não estamos apressados pelo relógio.

\section{Pique-Nique noturno}

Em conversa com alguns dos organizadores do evento (já realizado em diversas edições), um dos jornais da cidade, relata que seu surgimento se deu por um desejo de aproximar a alta gastronomia dos espaços públicos aliado à reivindicação de mais iluminação e segurança nesses mesmos espaços ${ }^{3}$. Em sua sétima edição, o Pique Nique noturno do Parcão aliou a sua proposta à hora do planeta, momento em que as pessoas são chamadas a apagarem as luzes como um gesto de alerta à crise ambiental e aos impactos do aquecimento global ${ }^{4}$. A chamada, em um dos jornais da cidade, convida a uma vivência de reflexão ambiental e gastronomia. Em

\footnotetext{
${ }^{2}$ Em seu livro "Comida como Cultura", Massimo Montanari, historiador italiano, aborda questões "culturais, naturais, de tempo, de espaço e dos conflitos sociais e pessoais que envolvem o comer e a fabricação de alimentos." $\mathrm{O}$ autor relaciona a cultura alimentar às formas de relação com a natureza, aos conflitos naturais ao longo da história e à formação dos grupos sociais. Busca demonstrar como as escolhas alimentares vão sendo delineadas por questões econômicas (disponibilidade), médicas (digestibilidade e nutrição) e que, vão levando ao de organizações sociais específicas. (RIBEIRO, 2011, p. 279)

3 Disponível em: http://m.zerohora.com.br/noticia/4575171/por-que-e-um-barato-comer-em-eventos-de-ruana-capital

4 Disponível em: http://kzuka.clicrbs.com.br/pop-up/noticia/2014/03/piquenique-noturno-com-os-chefs-rolaneste-sabado-em-porto-alegre-no-parcao-4458093.html
} 
outra ocasião, a chamada associa a ação a uma reivindicação por mais segurança e iluminação nos parques da capital gaúcha. Com o intuito de "iluminar o parque", as pessoas são convidadas a comparecerem vestidas de branco ${ }^{5}$. Em sua oitava edição, em junho de 2014, a chamada do evento menciona o esvaziamento dos parques no período da noite, pela falta de segurança e iluminação dos parques da cidade. Nesta edição também aparece a menção ao auxílio à campanha do agasalho, pois o pique-nique noturno seria transformado em um ponto de coleta desta iniciativa $^{6}$. Em outra edição ainda, as doações de litros de leite foram destinadas a um asilo da cidade. Assim, motivações filantrópicas começam também a orbitar junto à proposta de ocupação dos espaços da cidade, configurando modos de cidadania e organização social em prol de causas específicas que vão se modificando ao longo do tempo.

Figuras 1, 2 e 3: Pique-nique noturno no Parque Farroupilha
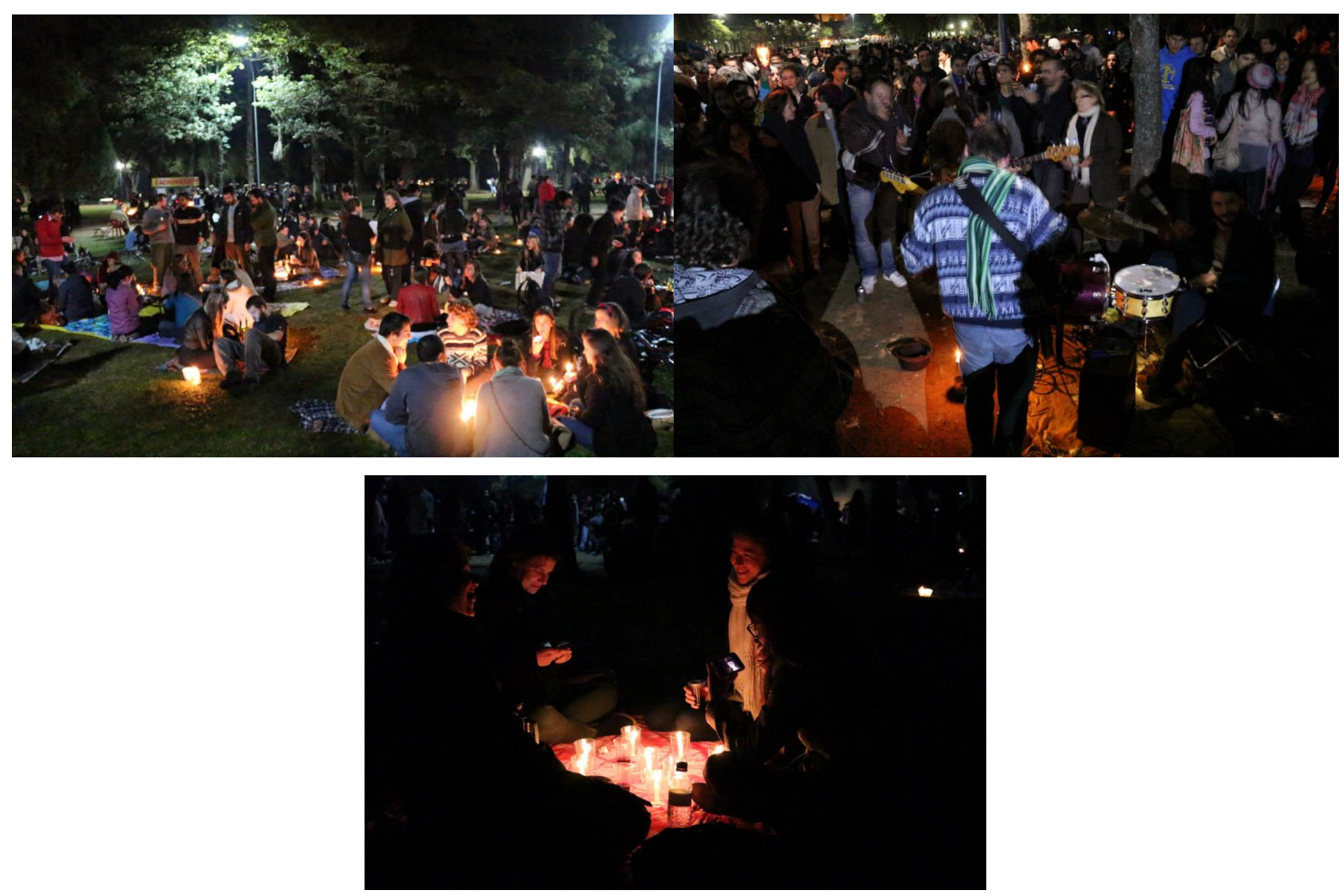

Fonte: Arquivo Pessoal

\footnotetext{
${ }^{5}$ Disponível em: http://www.hagah.com.br/especial/rs/gastronomia-rs/19,980,3869796,Piquenique-noturnocom-chefs-de-cozinha-acontece-nesse-sabado-no-Parcao.html

${ }^{6}$ Disponível em: https://catracalivre.com.br/porto-alegre/gastronomia/gratis/piquenique-noturno-vai-reunir-20chefs-de-cozinha-no-parcaol
} 
Figuras 4 e 5: Pique-nique noturno Parque Farroupilha

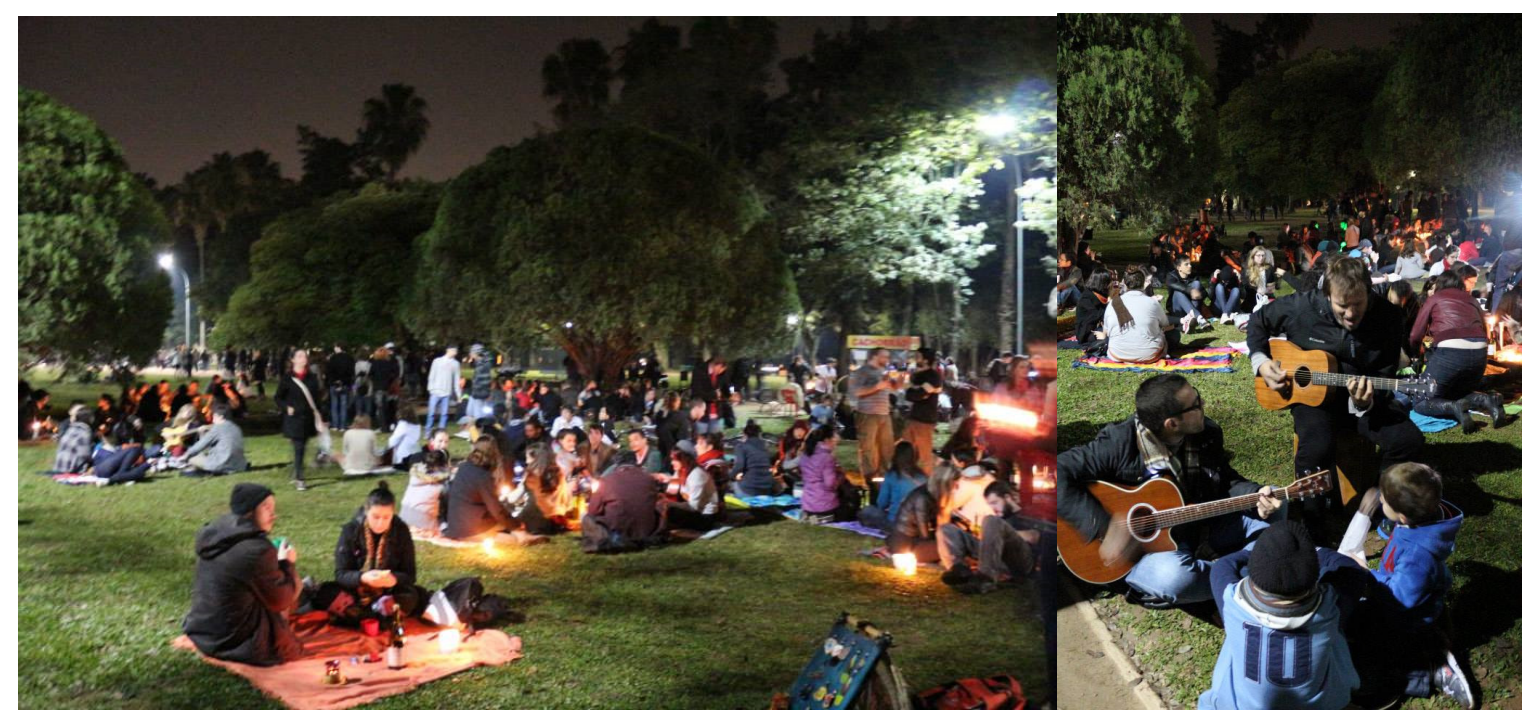

Fonte: Arquivo Pessoal

Na noite fria de 9 de junho de 2013, aconteceu uma das edições do Pique-nique noturno. Uma visão panorâmica iria identificar a disposição das pessoas como comum a um dia ensolarado em um final de semana qualquer. No entanto, por volta das onze horas da noite, milhares de pessoas se reuniram, sentadas em agrupamentos, ou transitando entre um grupo e outro. Muitas levaram velas, buscando evidenciar a importância da iluminação para a segurança dos locais na cidade. Artistas locais brindaram o público com pequenos shows, que aconteciam simultaneamente em diversos cantos do parque da Redenção. Algumas pessoas preferiram levar seus próprios instrumentos para arriscar um repertório mais particular em meio aos amigos. O som de violinos e violoncelos também circulou pela praça, com uma espécie de orquestra ambulante. Em outro lado do parque, amadores circences brincavam com malabares, bambolês e cordas. Os cachorros também fizeram parte da festa sendo levados por seus donos para um passeio noturno. A noite fria foi aquecida pelos encontros inusitados, pelo compartilhar dos alimentos e bebidas levados por cada um. As mais diversas tribos da cidade compartilhavam do espaço do Parque que, à noite, costuma ser um lugar associado ao perigo e à violência. Sem policiamento visível, a noite se estendeu de forma pacífica, embalada pelo espírito do agradável encontro. (Depoimento)

\section{Festival de Comida de Rua}

No ano de 2013, aconteceu o Festival de Comida de Rua de Porto Alegre, que também já foi realizado, depois disso, em diversas edições. O festival acontece na região central da 
cidade e, inspirado na proposta dos Food Trucks, reuniu centenas de pessoas - crianças, jovens, idosos em uma mesma localidade para desfrutar de aromas e sabores típicos de diversas partes do mundo, sob a responsabilidade de reconhecidos chefs de Porto Alegre. Este evento também congrega a intenção de aproximar a alta gastronomia dos espaços urbanos, da rua, popularizando-a. Como o pique-nique noturno, também possui caráter filantrópico, destinando doações para entidades assistenciais ${ }^{7}$.

\title{
Considerações Finais
}

A partir da possibilidade de abertura ao encontro e à interação no espaço público, de imersão dos sentidos - de poder ver, ouvir, cheirar, sentir o gosto - em um outro cenário que não o do habitual cotidiano que consideramos esses eventos em seu potencial para produzir uma outra experiência do espaço urbano, uma percepção capaz de engendrar outros modos de habitar a cidade. A arte e o lúdico também parecem compor este momento de ruptura e fazer parte da constituição de uma experiência diversa da paisagem, fazendo uso das sensações e do corpo. Ao perceber o ambiente com nossa atitude corpórea de modo artístico e criativo damos sentidos para o mundo que habitamos.

É possível, a partir dessas iniciativas refletir acerca da experiência de segurança em determinados espaços da cidade - em contraposição aos discursos de violência tão comumente incitados pela mídia -, da ocupação de espaços esvaziados, da interação e troca de saberes acerca do cotidiano, da experimentação de outros gostos e da popularização de seu acesso. Assim, aprende-se mais sobre a cidade e sua paisagem quando engajados nela - a paisagem marca sua presença no corpo possibilitando aos sujeitos sociais reconstruírem narrativas acerca do meio em que estão inseridos.

\section{EXPERIENCE, PERCEPTION AND URBAN SPACE: COEXISTENCE AND OCCUPATION REFRAMING THE INHABIT THE CITY}

\begin{abstract}
This paper aims to comprehend, considering Environmental Education and Environmental Psychology contributions, as well as Merleau-Ponty phenomenology's concepts of experience and perception, the effects of urban spaces occupation, taking two events held in the main parks of Porto Alegre city: the "Nightly picnic", which took place in Farroupilha and Moinhos de

7 Disponível em: http://redeglobo.globo.com/rs/rbstvrs/anonymusgourmet/noticia/2014/03/feira-comcomidas-de-rua-acontece-neste-domingo-15-na-cidade-baixa.html
\end{abstract}


Vento parks and the "Street Food Festival", held in the city central neighbourhoods. These two events are similar due to their goal to get both "haute cuisine" and public spaces closer, due to their philantropic character (donations to assistencial organizations) and because they can be considered as potencial spaces to produce a different experience of urban context and human relationshhip - among humans and between humans and urban environment. We understand that an experience possibility in this context might help to modify the people's perception about what is to live in the city and about the relationship of citizens with each other and with the environment in which they are engajed.

Key-words: Environmental Psychology; Environmental Education; Experience.

\section{EXPERIENCIA, PERCEPCIÓN Y ESPACIO URBANO: CONVIVENCIA Y OCUPACIÓN RESSIGNIFICANDO EL HABITAR DE LA CIUDAD}

\section{Resumen}

El presente artículo búsqueda comprender, a través de las contribuciones de la educación ambiental y de la psicología ambiental, así como de conceptos de experiencia y percepción en la fenomenologia de Merleau-Ponty, los efectos de la ocupación a través de dos eventos celebrados en los principales parques de la ciudad de Porto Alegre-RS: lo "Picnic Nocturno", celebrado en los parques Farroupilha y Molinos de Viento y el Festival de Comida callejera, celebrado en barrios céntricos de la ciudad.

Estos dos eventos se asemejan por aproximar el alta gastronomía de los espacios públicos, poseen carácter filantrópico, pues promueven donaciones de los participantes para entidades assistenciais y se presentan como espacios potenciales para una experiencia acerca del espacio urbano y de la convivencia de humanos entre sí y con el ambiente urbano.

Entendemos que la posibilidad de una experiencia en ese contexto puede contribuir para modificar la percepción de las personas acerca del habitar la ciudad y de la relación que establecen entre sí y con el ambiente en que están insertadas.

Palabras clave: Psicología Ambiental; Educación Ambiental; Experiencia.

\section{Referências}

CARVALHO, Isabel Cristina de Moura. Educação Ambiental: a formação do sujeito ecológico. 2.ed.São Paulo: Cortez, 2006.

CARVALHO, Isabel, STEIL, Carlos. Epistemologias Ecológicas: delimitando um conceito. Mana. Vol. 20, n.1, Rio de Janeiro. Abr. 2014.

CHAUÍ, M. Convite à Filosofia. 10.ed. São Paulo: Ática, 1998.

EVANS, G.W. Cognición ambiental. Estúdios de psicología n. 14/15. Departamento de Ecología Social, Universidad de California, Irving, 1983.

FAGGIONATO, Sandra. Percepção ambiental. Disponível em: http://educar.sc.usp.br/biologia/textos/m_a_txt4.html. Acessado em 18 nov 2014. 
INGOLD, Tim. Pare, olhe, escute - um prefácio. Revista Ponto Urbe. Ano 2. São Paulo. Jul. 2008 .

Da Transmissão de Representações à Educação da Atenção. Rev. Educação, Porto Alegre, v. 33, n. 1, p. 6-25, jan./abr. 2010.

GAUDIANO, E.G. Educação Ambiental. Instituto Piaget: Lisboa, 2005.

GUIMARÃES, M. A dimensão ambiental na educação. Campinas: Papirus, 1995

GUIMARÃES, M. Sustentabilidade e Educação Ambiental. In: SCHIEL, D.; VALEIRAS, N. (org.). O estudo de bacias hidrográficas - Uma estratégia para Educação Ambiental. São Carlos-SP:RIMA,2003.

HEEMANN, Ademar; HEEMANN, Nara. Natureza e percepção de valores. Desenvolvimento e Meio Ambiente, n. 7, p. 109-112, jan./jun. 2003. Editora UFPR.

KUHNEN, A.; HIGUCHI, M.I.H. Percepção ambiental. In: CAVALCANTI, S.; ELALI, G. A., organizadores. Temas Básicos em Psicologia Ambiental. Petrópolis-RJ: Vozes, 2011, p. 250266.

MATURANA, H.; VARELA, F. A árvore do conhecimento: as bases biológicas da compreensão humana. São Paulo: Palas Athena, 5. ed., 2005.

MERLEAU-PONTY, M. O Olho e o Espírito, In: Os Pensadores, São Paulo: Abril, 1975a.

A estrutura do comportamento. Belo Horizonte: Inter livros, $1975 \mathrm{~b}$.

. Signos. 1.ed. São Paulo: Martins Fontes, 1991.

. Fenomenologia da percepção. 2.ed. São Paulo: Martins Fontes,

1999.

MOSER, G. Psicologia Ambiental. Estudos de Psicologia. vol.3 n.1. Natal, Jan./June 1998. Disponível $\quad$ http://www.scielo.br/scielo.php?script=sci_arttext\&pid=S1413294X1998000100008 . Acessado em: 20 nov. 2014.

NOBREGA, Terezinha Petrucia da. Corpo, percepção e conhecimento em Merleau-Ponty. Estudos de Psicologia. Natal,n.13, 2008.

NOGUEIRA, J.C. A percepção como revelação do mundo: fenomenologia de Merleau-Ponty. Reflexão, Campinas, n.91, p. 19-26, 2007.

PAGNI, Pedro. Um lugar para a experiência e suas linguagens entre os saberes e práticas escolares: pensar a infância e o acontecimento na práxis educativa. In: PAGNI, Pedro; GELAMO, Rodrigo (Orgs.). Experiência, educação e contemporaneidade. Marília: Poiésis, 2010. 
RIBEIRO, Cilene da Silva Gomes. Comida como cultura. História: Questões \& Debates. Curitiba: Editora UFPR, n. 54, p. 279-282, jan./jun. 2011.

TUAN, Y.F. Topofilia: um estudo da percepção, atitudes e valores do meio ambiente. São Paulo: DIFEL, 1980.

YÁZIGI, E. A alma do lugar: turismo, planejamento e cotidiano. São Paulo: Contexto, 200

Data de recebimento: 05/12/14

Data de aceite: $28 / 07 / 16$

\section{Sobre as autoras:}

Chalissa Beatriz Wachholz é Graduada em Ciências Biológicas, atualmente é Doutoranda do Programa de Pós-Graduação da Pontifícia Universidade Católica do Rio Grande do Sul. Membro colaborador do Grupo de Pesquisa SobreNaturezas. Endereço eletrônico: chalibw@msn.com

Luciele Nardi Comunello é Graduada em Psicologia, atualmente é Doutoranda do Programa de Pós-Graduação da Pontifícia Universidade Católica do Rio Grande do Sul. Membro colaborador do Grupo de Pesquisa SobreNaturezas. Endereço eletrônico: lelicomunello@gmail.com 